\title{
A INFLUÊNCIA DAS VARIÁVEIS MICROCLIMÁTICAS NA DECISÃO PELO USO DA BICICLETA EM CENTROS URBANOS: UMA REVISÃO DA LITERATURA
}

\section{THE INFLUENCE OF MICROCLIMATIC VARIABLES IN THE DECISION FOR THE USE OF BICYCLE IN URBAN CENTRES: A LITERATURE REVIEW}

\author{
Mariana de Cillo Malufe Spignardi ${ }^{1}$ \\ Universidade de São Paulo, São Paulo, São Paulo, Brasil, mariana.malufe@usp.br \\ Leonardo Marques Monteiro 2 \\ Universidade de São Paulo, São Paulo, São Paulo, Brasil, leo4mm@usp.br
}

\section{Resumo}

Este artigo se propõe a fazer uma revisão da literatura a respeito da correlação entre variáveis microclimáticas como temperatura média do ar, níveis de precipitação e velocidade do vento com a decisão pelo uso da bicicleta em centros urbanos. O artigo contém a sistematização do processo de revisão da literatura, dividido em duas etapas: (1) identificação e seleção dos artigos e (2) análise sistemática do conteúdo, consolidando as principais colocações dos autores. Foi identificado que as variáveis microclimáticas influenciam usuários de transportes ativos, como pedestres e ciclistas, e que a variação na temperatura média do ar e a presença de precipitação são os aspectos de maior influência na decisão pelo uso da bicicleta, tanto para percursos utilitários quanto para recreativos, sendo estes os mais impactados. Outros aspectos que influenciam o uso da bicicleta, como os socioeconômicos e culturais, também são abordados de forma a complementar a análise da influência das variáveis ambientais. A contribuição deste artigo se dá pela sistematização do método empregado na pesquisa bibliográfica e das correlações identificadas por outros autores entre variáveis microclimáticas e o uso da bicicleta em centros urbanos.

Palavras-chave: Mobilidade. Bicicleta. Conforto ambiental.

\begin{abstract}
This article aims at making a literature review concerning the correlation of microclimatic variables such as mean air temperature, precipitation levels, and air speed, and the decision for the use of bicycle in urban centres. The article contains the systematization of the literature review process divided into two steps: (1) identification and selection of articles, and (2) systematic analysis of content, reinforcing the main findings of the authors. Microclimatic variables influence users of active transports, such as pedestrians and cyclists. Another finding was the variation of mean air temperature and precipitation, being the most influential aspects on deciding to use bicycle, for both utility and leisure routes, the latter being the most affected. Other aspects influencing the use of bicycle, such as socioeconomic and cultural ones, are also mentioned in order to complement the analysis of the impact of the microclimatic variables. The contribution of this article is the systematization of the method used in the bibliographical review and the correlations identified by other authors between microclimatic variables and the use of bicycle in urban centres.
\end{abstract}

Keywords: Mobility. Bicycle. Environmental comfort.

How to cite this article:

SPIGNARDI, Mariana de Cillo Malufe; MONTEIRO, Leonardo Marques. A influência das variáveis microclimáticas na decisão pelo uso da bicicleta em centros urbanos: uma revisão da literatura. PARC Pesquisa em Arquitetura e Construção, Campinas, SP, v. 8, n. 4, p. 220-235, dez. 2017. ISSN 1980-6809. Disponível em: <https://periodicos.sbu.unicamp.br/ojs/index.php/parc/article/view/8650215>. Acesso em: 26 fev. 2018. doi:https://doi.org/10.20396/parc.v8i4.8650215. 


\section{Introdução}

O uso da bicicleta como meio de transporte é uma peçachave na construção de sistemas de mobilidade urbana mais sustentáveis e no desenvolvimento de centros urbanos de menor impacto ambiental. Os transportes ativos, em especial a bicicleta, são uma opção saudável e de baixo custo para os usuários, contribuindo inclusive com a democratização do acesso aos sistemas de transporte. Pode não ser a melhor opção para vencer longas distâncias, mas pode ser muito útil para percursos de até $5 \mathrm{~km}$. Sabir (2011) coloca que, em grande parte dos centros urbanos, aproximadamente $75 \%$ dos percursos para o trabalho são de até $5 \mathrm{~km}$.

A escolha diária por um meio de transporte para se deslocar ao trabalho é influenciada por atitudes pessoais, aspectos socioeconômicos e fatores demográficos, características dos percursos como distância e topografia, e por variações climáticas (BERGSTROM; MAGNUSSON, 2003). Aaheim e Hauge (2005) e Ahmed et al. (2010) entendem as variáveis climáticas como um dos aspectos que mais influenciam os hábitos de viagem dos usuários dos diversos modos de transporte. Aaheim e Hauge (2005) apontam ainda para mudanças significativas na divisão modal de transportes, fruto de pequenas mudanças em variáveis ambientais. Sabir (2011) identifica uma correlação entre o aumento da precipitação e velocidade do vento e o aumento no uso do transporte público, em especial do metrô, em detrimento de outros meios de transporte como a bicicleta.

Assim, apesar do potencial da bicicleta em contribuir com centros urbanos mais sustentáveis e das inúmeras iniciativas de fomento espalhadas pela Europa, América do Norte e Oceania, os ciclistas são influenciados por diversos aspectos, entre eles, as variações microclimáticas.

Considerando essa problemática, a presente revisão bibliográfica objetiva identificar em que extensão a literatura científica identifica correlações entre as variáveis microclimáticas e a decisão do ciclista pelo uso da bicicleta em centros urbanos.

\section{Método}

Este processo de revisão da literatura divide-se em duas etapas: (i) identificação e seleção dos artigos, e (ii) análise sistemática do conteúdo.

\section{Identificação e seleção dos artigos}

Durante a fase de desenvolvimento do projeto de pesquisa, foi feita a leitura de artigos e publicações identificados através de um processo de busca não sistematizado. Essa primeira aproximação ao tema, feita em bancos de dados que concentram periódicos nacionais, internacionais e anais de eventos, permitiu a identificação de:

a. Bancos de dados que concentram as publicações mais relevantes sobre o tema e bancos de dados nacionais;

b. Palavras-chave, utilizadas para refinar a busca sistematizada.

A identificação dos artigos foi baseada na análise sistemática dos bancos de dados SCOPUS, WEB OF SCIENCE, INFOHAB e anais dos eventos PLURIS, ENCAC e ELACAC.

Para entender a correlação entre o microclima urbano e o uso da bicicleta como meio de transporte, foram definidas sete palavras-chave, sendo quatro para identificar os aspectos relacionados às questões climáticas (\#weather, \#climate, \#environmental factors, \#thermal confort) e três para identificar aspectos relacionados às questões ligadas ao uso da bicicleta (\#cycling, \#bicycle, \#active transportation). As buscas continham no título, resumo ou como palavra-chave uma das quatro palavras-chave ligadas às questões climáticas e uma das três palavraschave ligadas ao uso da bicicleta, totalizando 12 buscas em cada um dos bancos de dados. Para as buscas em bancos de dados nacionais, também foram utilizadas quatro palavras-chave na língua portuguesa para a identificação de aspectos climáticos (\#microclima, \#clima, \#variáveis ambientais, \#conforto térmico) e três para o uso da bicicleta (\#ciclismo, \#bicicleta, \#transporte ativo).

$\mathrm{Na}$ busca feita no SCOPUS, foram consideradas publicações de todos os tipos de documentos listados, publicados até junho de 2017. Em uma segunda etapa, cada busca foi limitada às disciplinas relacionadas ao tema (engineering e environmental science) e posteriormente foram selecionadas as publicações que seriam estudadas. Para cada busca contendo duas palavras-chave, a quantidade de documentos identificados nas três etapas foi a indicada na Tabela 1 .

Foram selecionados 90 documentos e eliminados aqueles que apareceram em mais de uma busca, resultando em um total de 56 documentos.

Na busca feita no WEB OF SCIENCE, foram consideradas publicações de todos os tipos de documentos listados, publicados até junho de 2017. Em uma segunda etapa, as buscas foram limitadas às disciplinas relacionadas ao tema (Engineering Environmental, Transportation, Engineering Multidisciplinary, Behavioral Sciences) e posteriormente foram selecionadas as publicações que seriam estudadas. Foram feitas 12 buscas, fazendo uso das mesmas palavras-chave da pesquisa feita no SCOPUS. A quantidade de documentos identificados é apresentado na Tabela 2. 
Tabela 1 - Busca feita no banco de dados SCOPUS.

\begin{tabular}{cccc} 
SCOPUS - palavras-chave & $\begin{array}{c}\text { Documentos identificados } \\
\text { na primeira etapa }\end{array}$ & $\begin{array}{c}\text { Documentos identificados } \\
\text { na segunda etapa }\end{array}$ & $\begin{array}{c}\text { Documentos selecionados para } \\
\text { leitura }\end{array}$ \\
\hline Weather AND Cycling & 727 & 337 & 19 \\
\hline Weather AND Bicycle & 217 & 127 & 25 \\
\hline Weather AND Active Transportation & 136 & 79 & 6 \\
\hline Climate AND Cycling & 5.461 & 2.727 & 7 \\
\hline Climate AND Bicycle & 241 & 94 & 14 \\
\hline Climate AND Active Transportation & 160 & 89 & 4 \\
\hline Environmental Factors AND Cycling & 3.057 & 1.531 & 2 \\
\hline Environmental Factors AND Bicycle & 504 & 201 & 2 \\
\hline Environmental Factors AND Active Transportation & 341 & 116 & \\
\hline Thermal Comfort AND Cycling & 90 & 31 & 1 \\
\hline Thermal Comfort AND Bicycle & 51 & 18 & 1 \\
\hline Thermal Comfort AND Active Transportation & 11 & 7 & 1 \\
\hline
\end{tabular}

Fonte: Os autores

Tabela 2 - Busca feita no banco de dados Web of Science.

\begin{tabular}{|c|c|c|c|}
\hline WEB OF SCIENCE - palavras-chave & $\begin{array}{c}\text { Documentos identificados } \\
\text { na primeira etapa }\end{array}$ & $\begin{array}{l}\text { Documentos identificados } \\
\text { na segunda etapa }\end{array}$ & $\begin{array}{c}\text { Documentos selecionados para } \\
\text { leitura }\end{array}$ \\
\hline Weather AND Cycling & 10.535 & 340 & 10 \\
\hline Weather AND Bicycle & 152 & 77 & 21 \\
\hline Weather AND Active Transportation & 16 & 6 & 2 \\
\hline Climate AND Cycling & 41.024 & 1.715 & 9 \\
\hline Climate AND Bicycle & 135 & 53 & 16 \\
\hline Climate AND Active Transportation & 15 & 3 & 3 \\
\hline Environmental Factors AND Cycling & 3.689 & 144 & 1 \\
\hline Environmental Factors AND Bicycle & 81 & 22 & 2 \\
\hline Environmental Factors AND Active Transportation & 32 & 5 & -- \\
\hline Thermal Comfort AND Cycling & 418 & 52 & 2 \\
\hline Thermal Comfort AND Bicycle & 38 & 10 & --- \\
\hline Thermal Comfort AND Active Transportation & 2 & --- & --- \\
\hline
\end{tabular}

Fonte: Os autores

No INFOHAB foram feitas 12 buscas, fazendo uso das mesmas palavras-chave na língua inglesa. Em seguida foram feitas outras 12 buscas com palavras-chave na língua portuguesa, relacionando \#microclima, \#clima, \#variáveis ambientais e \#conforto térmico com \#ciclismo, \#bicicleta e \#transporte ativo, porém não foi encontrado nenhum documento. Foi feito um refinamento da busca, usando apenas uma palavra-chave relativa ao uso da bicicleta (\#ciclismo, \#bicicleta, \#transporte ativo), e apenas na busca com a palavra-chave \#bicicleta foram encontrados três artigos indiretamente relacionados ao tema. Foi feita uma busca nos anais de todas as edições dos eventos PLURIS, ENCAC e ELACAC, onde não foram encontrados artigos abordando diretamente a correlação entre condições microclimáticas e/ou climáticas e o uso de bicicletas.

Foram selecionados 69 documentos. A busca identificou um número maior de documentos, mas alguns apareceram em mais de um processo de busca ou abordam o tema de forma indireta. Foi feita uma análise do conteúdo dos referidos artigos e da relevância dos mesmos para o trabalho. Foram analisados sistematicamente neste artigo apenas aqueles que tratam diretamente do tema.

Em seguida, teve início a etapa de identificação de publicações referenciadas na bibliografia dos artigos selecionados, que resultaram em uma busca pontual em outros bancos de dados.

\section{Análise sistemática do conteúdo}

Durante a leitura e análise dos artigos, foram selecionados os temas e conteúdos abordados relevantes para $\mathrm{o}$ entendimento da correlação entre microclima e o uso da bicicleta como meio de transporte.

As principais abordagens dos artigos selecionados foram agrupadas de acordo com os seguintes assuntos:

a. Escala de abordagem, que identifica a escala física da pesquisa e varia entre a escala local, com medições microclimáticas, escalas regionais, entre cidades, e nacionais;

b. Contexto social, considerando a região em que os estudos foram realizados;

c. Variáveis ambientais consideradas, como temperatura e umidade relativa do ar, níveis de precipitação, velocidade do vento, horas de sol por dia, entre outros;

d. Outras variáveis, como dados socioeconômicos, de morfologia e tipologia urbana, infraestrutura cicloviária, propósito da viagem, entre outros; 
e. Método de coleta de dados, identificando se os dados foram coletados por estações meteorológicas, medições de campo, contagem eletrônica de bicicletas ou informações de agências de transporte, por exemplo;

f. Processo de análise de dados, indicando se as variáveis ambientais foram avaliadas de forma isolada ou combinada, se os dados climáticos e de fluxo de bicicletas foram consolidados por hora ou por dia, entre outros; g. Resultados, que consolida os principais entendimentos dos autores sobre o tema, muitas vezes opostos ou discordantes, mas que permite consolidar os entendimentos que estão mais presentes nos artigos.

Foram elaborados os Quadros 1, 2 e 3, que sintetizam as principais abordagens, métodos de coleta e análise de dados e colocações de cada artigo.

Quadro 1 - Síntese da revisão da literatura: escala de abordagem, contexto social e variáveis ambientais

\begin{tabular}{|c|c|c|c|c|c|c|c|c|c|c|c|c|c|c|c|c|c|c|c|c|c|c|c|}
\hline \multirow{2}{*}{ 迹 } & \multirow[b]{2}{*}{ Referência } & \multicolumn{5}{|c|}{ Escala de Abordagem } & \multicolumn{5}{|c|}{ Contexto Social } & \multicolumn{12}{|c|}{ Variáveis Ambientais } \\
\hline & & $\begin{array}{l}\text { Área de } \\
\text { estudo }\end{array}$ & 1 & 2 & 3 & 4 & 5 & 6 & 7 & 8 & 9 & A & B & C & D & $\mathrm{E}$ & $F$ & G & H & I & $\mathrm{J}$ & K & $\mathbf{L}$ \\
\hline 1 & (AAHEIM; HAUGE, 2005) & $\begin{array}{l}\text { Bergen, } \\
\text { Norway }\end{array}$ & & & & & & & & & & & & & & & & & & & & & \\
\hline 2 & $\begin{array}{c}\text { (AHMED; ROSE; JAKOB, } \\
\text { 2010) }\end{array}$ & $\begin{array}{l}\text { Melborne, } \\
\text { Austrália }\end{array}$ & & & & & & & & & & & & & & & & & & & & & \\
\hline 3 & (AHMED et al., 2012) & $\begin{array}{l}\text { Portland, EUA } \\
\text { e Brisbane, } \\
\text { Austrália } \\
\end{array}$ & & & & & & & & & & & & & & & & & & & & & \\
\hline 4 & $\begin{array}{c}\text { (AHMED; ROSE; JAKOB, } \\
\text { 2013a) }\end{array}$ & $\begin{array}{l}\text { Victoria, } \\
\text { Australia }\end{array}$ & & & & & & & & & & & & & & & & & & & & & \\
\hline 5 & $\begin{array}{l}\text { (AHMED; ROSE; JAKOB, } \\
\text { 2013b) }\end{array}$ & $\begin{array}{l}\text { Victoria, } \\
\text { Australia }\end{array}$ & & & & & & & & & & & & & & & & & & & & & \\
\hline 6 & $\begin{array}{l}\text { (AMIRI; SADEGHPOUR, } \\
\text { 2013) }\end{array}$ & $\begin{array}{l}\text { Calgary, } \\
\text { Canadá }\end{array}$ & & & & & & & & & & & & & & & & & & & & & \\
\hline 7 & $\begin{array}{l}\text { (AMIRI; SADEGHPOUR, } \\
\text { 2015) }\end{array}$ & $\begin{array}{l}\text { Calgary, } \\
\text { Canadá }\end{array}$ & & & & & & & & & & & & & & & & & & & & & \\
\hline 8 & $\begin{array}{c}\text { (BERGSTROM; } \\
\text { MAGNUSSON, 2003) }\end{array}$ & $\begin{array}{l}\text { Lulea e } \\
\text { Linkoping, } \\
\text { Suécia }\end{array}$ & & & & & & & & & & & & & & & & & & & & & \\
\hline 9 & $\begin{array}{l}\text { (BOCKER; DIJST; } \\
\text { PRILLWITZ, 2013) }\end{array}$ & $\begin{array}{c}\text { Revisão } \\
\text { bibliográfica }\end{array}$ & & & & & & & & & & & & & & & & & & & & & \\
\hline 10 & $\begin{array}{l}\text { (BOCKER; PRILLWITZ; } \\
\text { DIJST, 2013b) }\end{array}$ & $\begin{array}{l}\text { Região de } \\
\text { Rotterdam, } \\
\text { Holanda }\end{array}$ & & & & & & & & & & & & & & & & & & & & & \\
\hline 11 & $\begin{array}{c}\text { (BOCKER; THORSSON, } \\
\text { 2014) }\end{array}$ & $\begin{array}{l}\text { Região de } \\
\text { Rotterdam, } \\
\text { Holanda }\end{array}$ & & & & & & & & & & & & & & & & & & & & & \\
\hline 12 & (BOCKER et al., 2015) & $\begin{array}{l}\text { Região de } \\
\text { Rotterdam, } \\
\text { Holanda }\end{array}$ & & & & & & & & & & & & & & & & & & & & & \\
\hline 13 & $\begin{array}{c}\text { (BOCKER; DIJST; FABER, } \\
\text { 2016) }\end{array}$ & $\begin{array}{l}\text { Região de } \\
\text { Rotterdam, } \\
\text { Holanda }\end{array}$ & & & & & & & & & & & & & & & & & & & & & \\
\hline 14 & $\begin{array}{c}\text { (BRANDENBURG; } \\
\text { MATZARAKIS; ARNBERGER, } \\
\text { 2004) } \\
\end{array}$ & $\begin{array}{l}\text { Vienna, } \\
\text { Austria }\end{array}$ & & & & & & & & & & & & & & & & & & & & & \\
\hline 15 & $\begin{array}{c}\text { (BRANDENBURG; } \\
\text { MATZARAKIS; ARNBERGER, } \\
2007)\end{array}$ & $\begin{array}{l}\text { Vienna, } \\
\text { Austria }\end{array}$ & & & & & & & & & & & & & & & & & & & & & \\
\hline 16 & (CLIFTON; CHEN, 2011) & $\begin{array}{l}\text { Região de } \\
\text { Sydney, } \\
\text { Austrália }\end{array}$ & & & & & & & & & & & & & & & & & & & & & \\
\hline 17 & (CORCORAN et al., 2014) & $\begin{array}{l}\text { Brisbane, } \\
\text { Australia }\end{array}$ & & & & & & & & & & & & & & & & & & & & & \\
\hline 18 & (EL-ASSI et al., 2017) & $\begin{array}{l}\text { Toronto, } \\
\text { Canadá } \\
\end{array}$ & & & & & & & & & & & & & & & & & & & & & \\
\hline 19 & $\begin{array}{l}\text { (EMMERSON; RYLEY; } \\
\text { DAVIES, 1998) }\end{array}$ & $\begin{array}{l}\text { Chingford e } \\
\text { Bidston, } \\
\text { Reino Unido }\end{array}$ & & & & & & & & & & & & & & & & & & & & & \\
\hline
\end{tabular}


SPIGNARDI, Mariana de Cillo Malufe; MONTEIRO, Leonardo Marques.

A influência das variáveis microclimáticas na decisão pelo uso da bicicleta em centros urbanos: uma revisão da literatura

Quadro 1 - Síntese da revisão da literatura: escala de abordagem, contexto social e variáveis ambientais

\begin{tabular}{|c|c|c|c|c|c|c|c|c|c|c|c|c|c|c|c|c|c|c|c|c|c|c|c|}
\hline \multirow{2}{*}{ 은 } & \multirow[b]{2}{*}{ Referência } & \multicolumn{5}{|c|}{ Escala de Abordagem } & \multicolumn{5}{|c|}{ Contexto Social } & \multicolumn{12}{|c|}{ Variáveis Ambientais } \\
\hline & & $\begin{array}{l}\text { Área de } \\
\text { estudo }\end{array}$ & 1 & 2 & 3 & 4 & 5 & 6 & 7 & 8 & 9 & A & B & C & D & E & $\mathbf{F}$ & G & $\mathrm{H}$ & I & $J$ & K & $\mathrm{L}$ \\
\hline 20 & $\begin{array}{c}\text { (ENGBERS; HENDRIKSE, } \\
\text { 2010) }\end{array}$ & Holanda & & & & & & & & & & & & & & & & & & & & & \\
\hline 21 & (FLYNN; et al., 2012) & Vermont, EUA & & & & & & & & & & & & & & & & & & & & & \\
\hline 22 & (GALLOP; TSE, 2012) & $\begin{array}{l}\text { Vancouver, } \\
\text { Canadá }\end{array}$ & & & & & & & & & & & & & & & & & & & & & \\
\hline 23 & (GEBHART; NOLAND, 2013) & $\begin{array}{l}\text { Washington } \\
\text { DC, EUA }\end{array}$ & & & & & & & & & & & & & & & & & & & & & \\
\hline 24 & (HANSON; HANSON, 1977) & $\begin{array}{l}\text { Uppsala, } \\
\text { Suécia }\end{array}$ & & & & & & & & & & & & & & & & & & & & & \\
\hline 25 & $\begin{array}{c}\text { (HEINEN; VAN WEE; MAAT, } \\
\text { 2010) }\end{array}$ & $\begin{array}{c}\text { Revisão } \\
\text { bibliográfica }\end{array}$ & & & & & & & & & & & & & & & & & & & & & \\
\hline 26 & $\begin{array}{c}\text { (HEINEN; VAN WEE; MAAT, } \\
\text { 2011) }\end{array}$ & $\begin{array}{c}\text { Delft e Zwolle, } \\
\text { Holanda }\end{array}$ & & & & & & & & & & & & & & & & & & & & & \\
\hline 27 & $\begin{array}{c}\text { (HELBICH; BOCKER; DIJST, } \\
\text { 2014) }\end{array}$ & $\begin{array}{l}\text { Região de } \\
\text { Rotterdam, } \\
\text { Holanda }\end{array}$ & & & & & & & & & & & & & & & & & & & & & \\
\hline 28 & (LIU et al., 2015) & Suécia & & & & & & & & & & & & & & & & & & & & & \\
\hline 29 & $\begin{array}{c}\text { (MATHISEN; KROESEN, } \\
\text { 2015) }\end{array}$ & $\begin{array}{c}\text { Bodo, } \\
\text { Noruega }\end{array}$ & & & & & & & & & & & & & & & & & & & & & \\
\hline 30 & $\begin{array}{c}\text { (MENG; ZHANG; WONG, } \\
\text { 2016) }\end{array}$ & Cingapura & & & & & & & & & & & & & & & & & & & & & \\
\hline 31 & $\begin{array}{c}\text { (MIRANDA-MORENO; } \\
\text { NOSAL, 2011) }\end{array}$ & $\begin{array}{l}\text { Montreal, } \\
\text { Canadá }\end{array}$ & & & & & & & & & & & & & & & & & & & & & \\
\hline 32 & $\begin{array}{l}\text { (MIRANDA-MORENO et al., } \\
\text { 2014) }\end{array}$ & $\begin{array}{c}\text { Montreal, } \\
\text { Ottawa, } \\
\text { Portland, São } \\
\text { Francisco, } \\
\text { Vancouver }\end{array}$ & & & & & & & & & & & & & & & & & & & & & \\
\hline 33 & (MOTOAKI; DAZIANO, 2015) & $\begin{array}{l}\text { Nova York, } \\
\text { EUA }\end{array}$ & & & & & & & & & & & & & & & & & & & & & \\
\hline 34 & (NANKERVIS, 1999) & $\begin{array}{c}\text { Melbourne, } \\
\text { Austrália }\end{array}$ & & & & & & & & & & & & & & & & & & & & & \\
\hline 35 & $\begin{array}{l}\text { (NOSAL; MIRANDA- } \\
\text { MORENO, 2014) }\end{array}$ & $\begin{array}{c}\text { Montreal, } \\
\text { Ottawa, } \\
\text { Portland, } \\
\text { Vancouver, } \\
\text { Quebec }\end{array}$ & & & & & & & & & & & & & & & & & & & & & \\
\hline 36 & $\begin{array}{c}\text { (PARKIN; WARDMAN; PAGE, } \\
\text { 2008) }\end{array}$ & UK & & & & & & & & & & & & & & & & & & & & & \\
\hline 37 & (PHUNG; ROSE, 2008) & $\begin{array}{c}\text { Melbourne, } \\
\text { Austrália }\end{array}$ & & & & & & & & & & & & & & & & & & & & & \\
\hline 38 & (PUCHER; BUEHLER, 2006) & $\begin{array}{l}\text { Canadá e } \\
\text { EUA }\end{array}$ & & & & & & & & & & & & & & & & & & & & & \\
\hline 39 & (PUCHER; BUEHLER, 2008a) & $\begin{array}{l}\text { Holanda, } \\
\text { Dinamarca e } \\
\text { Alemanha }\end{array}$ & & & & & & & & & & & & & & & & & & & & & \\
\hline 40 & (PUCHER; BUEHLER, 2008b) & $\begin{array}{l}\text { Holanda, } \\
\text { Dinamarca e } \\
\text { Alemanha }\end{array}$ & & & & & & & & & & & & & & & & & & & & & \\
\hline 41 & (RICHARDSON, 2000) & $\begin{array}{c}\text { Melbourne, } \\
\text { Austrália }\end{array}$ & & & & & & & & & & & & & & & & & & & & & \\
\hline 42 & (SABIR, 2011) & Holanda & & & & & & & & & & & & & & & & & & & & & \\
\hline 43 & $\begin{array}{c}\text { (SAELENS; SALLIS; FRANK, } \\
\text { 2003) }\end{array}$ & ('não define) & & & & & & & & & & & & & & & & & & & & & \\
\hline 44 & $\begin{array}{c}\text { (SANEINEJAD; KENNEDY; } \\
\text { ROORDA, 2010) }\end{array}$ & $\begin{array}{l}\text { Toronto, } \\
\text { Canadá }\end{array}$ & & & & & & & & & & & & & & & & & & & & & \\
\hline 45 & $\begin{array}{c}\text { (SANEINEJAD; ROORDA; } \\
\text { KENNEDY, 2012) }\end{array}$ & $\begin{array}{l}\text { Toronto, } \\
\text { Canadá }\end{array}$ & & & & & & & & & & & & & & & & & & & & & \\
\hline 46 & (SEARS et al., 2012) & Vermont, EUA & & & & & & & & & & & & & & & & & & & & & \\
\hline
\end{tabular}


SPIGNARDI, Mariana de Cillo Malufe; MONTEIRO, Leonardo Marques.

A influência das variáveis microclimáticas na decisão pelo uso da bicicleta em centros urbanos: uma revisão da literatura

Quadro 1 - Síntese da revisão da literatura: escala de abordagem, contexto social e variáveis ambientais

\begin{tabular}{|c|c|c|c|c|c|c|c|c|c|c|c|c|c|c|c|c|c|c|c|c|c|c|c|}
\hline \multirow{2}{*}{$\begin{array}{l}\text { 은 } \\
\text { 톨 } \\
\text { 之 }\end{array}$} & \multirow[b]{2}{*}{ Referência } & \multicolumn{5}{|c|}{ Escala de Abordagem } & \multicolumn{5}{|c|}{ Contexto Social } & \multicolumn{12}{|c|}{ Variáveis Ambientais } \\
\hline & & $\begin{array}{l}\text { Área de } \\
\text { estudo }\end{array}$ & 1 & 2 & 3 & 4 & 5 & 6 & 7 & 8 & 9 & A & B & C & D & $\mathbf{E}$ & $\mathbf{F}$ & G & $\mathrm{H}$ & I & $\mathbf{J}$ & K & $\mathbf{L}$ \\
\hline 47 & (SILVEIRA; MAIA, 2015) & (não define) & & & & & & & & & & & & & & & & & & & & & \\
\hline 48 & (SMITH; KAUERMANN, 2011) & $\begin{array}{l}\text { Melbourne, } \\
\text { Austrália }\end{array}$ & & & & & & & & & & & & & & & & & & & & & \\
\hline 49 & (SPENCER et al., 2013) & Vermont, EUA & & & & & & & & & & & & & & & & & & & & & \\
\hline 50 & $\begin{array}{l}\text { (THOMAS; JAARSMA; } \\
\text { TUTERT, 2009) }\end{array}$ & $\begin{array}{c}\text { Gouda e Ede, } \\
\text { Holanda }\end{array}$ & & & & & & & & & & & & & & & & & & & & & \\
\hline 51 & $\begin{array}{c}\text { (THOMAS; JAARSMA; } \\
\text { TUTERT, 2013) }\end{array}$ & Holanda & & & & & & & & & & & & & & & & & & & & & \\
\hline 52 & (TIN TIN; et al., 2012) & $\begin{array}{c}\text { Auckland, } \\
\text { Nova Zelândia }\end{array}$ & & & & & & & & & & & & & & & & & & & & & \\
\hline 53 & (WADUD, 2013) & London, UK & & & & & & & & & & & & & & & & & & & & & \\
\hline 54 & $\begin{array}{c}\text { (WARDMAN; TIGHT; PAGE, } \\
\text { 2007) }\end{array}$ & Reino Unido & & & & & & & & & & & & & & & & & & & & & \\
\hline 55 & (WINTERS et al., 2007) & Canadá & & & & & & & & & & & & & & & & & & & & & \\
\hline 56 & (WINTERS et al., 2011) & $\begin{array}{l}\text { Vancouver, } \\
\text { Canadá }\end{array}$ & & & & & & & & & & & & & & & & & & & & & \\
\hline
\end{tabular}

Legenda: Nacional; 2- Regional entre cidades; 3- Local Nível cidade; 4- Local Nível II, locais específicos; 5-Noroeste Europeu; 6- Norte Americano; 7- Australiano; 8- América do Sul; 9- Ásia; A- Temperatura do ar; B-Umidade Relativa do ar; C- Precipitação; D- Velocidade do Vento; E- Horas de Sol/Dia; F- Cobertura do Céu; G- Névoa/ Neblina visibilidade; HCondições do piso altura da neve; I- Temperatura; J- Radiante Média - temp. de globo e Radiação solar direta e difusa (global + difusa); K- Temperatura aparente; L- Parâmetros

Fisiológicos roupas e metabolismo. Fonte: Os autores

Quadro 2 - Síntese da revisão da literatura: outras variáveis, coleta e análise de dados

\begin{tabular}{|c|c|c|c|c|c|c|c|c|c|c|c|c|c|c|c|c|c|c|c|c|c|c|c|c|c|c|c|c|c|c|c|c|c|c|c|}
\hline & Outras & s Varie & áveis & & & & & & & Colet & ade da & ddos & & & & & & & & Anális & seded & dados & & & & & & & & & & & & & \\
\hline 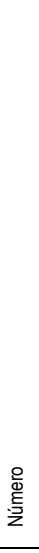 & 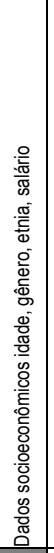 & 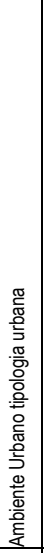 & 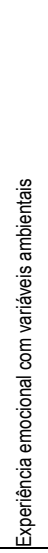 & 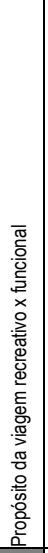 & 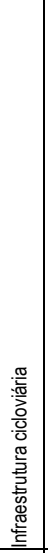 & 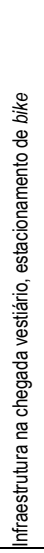 & 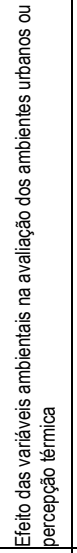 & 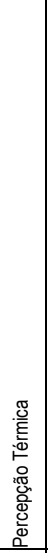 & 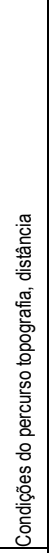 & 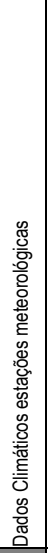 & 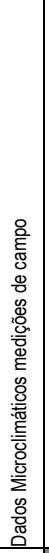 & 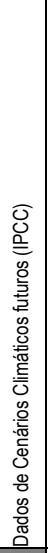 & 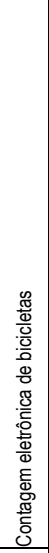 & 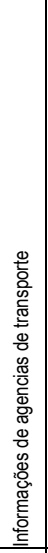 & 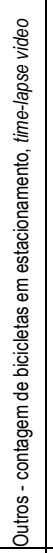 & 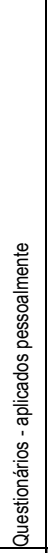 & 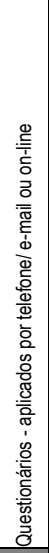 & 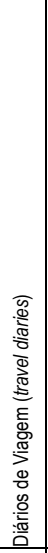 & 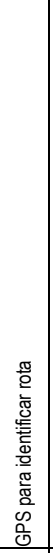 & 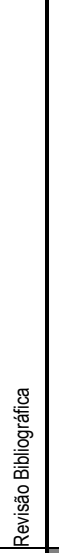 & 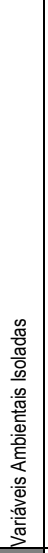 & 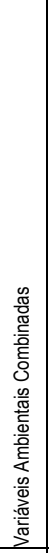 & 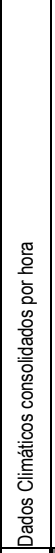 & 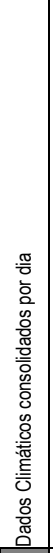 & 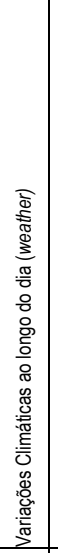 & 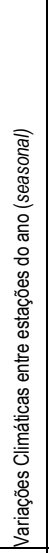 & 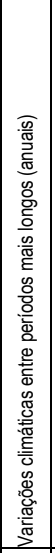 & 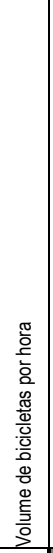 & 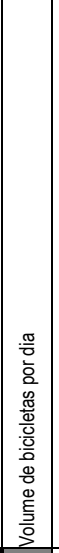 & 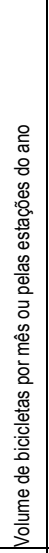 & 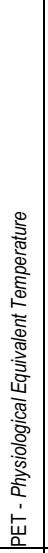 & 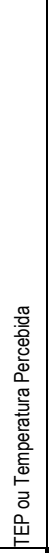 & 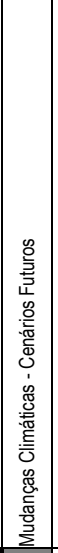 & 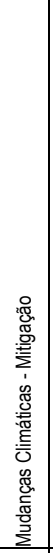 & 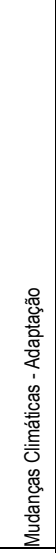 \\
\hline 1 & & & & & & & & & & & & & & & & & & & & & & & & & & & & & & & & & & & \\
\hline 2 & & & & & & & & & & & & & & & & & & & & & & & & & & & & & & & & & & & \\
\hline 3 & & & & & & & & & & & & & & & & & & & & & & & & & & & & & & & & & & & \\
\hline 4 & & & & & & & & & & & & & & & & & & & & & & & & & & & & & & & & & & & \\
\hline 5 & & & & & & & & & & & & & & & & & & & & & & & & & & & & & & & & & & & \\
\hline 6 & & & & & & & & & & & & & & & & & & & & & & & & & & & & & & & & & & & \\
\hline 7 & & & & & & & & & & & & & & & & & & & & & & & & & & & & & & & & & & & \\
\hline 8 & & & & & & & & & & & & & & & & & & & & & & & & & & & & & & & & & & & \\
\hline 9 & & & & & & & & & & & & & & & & & & & & & & & & & & & & & & & & & & & \\
\hline 10 & & & & & & & & & & & & & & & & & & & & & & & & & & & & & & & & & & & \\
\hline 11 & & & & & & & & & & & & & & & & & & & & & & & & & & & & & & & & & & & \\
\hline 12 & & & & & & & & & & & & & & & & & & & & & & & & & & & & & & & & & & & \\
\hline 13 & & & & & & & & & & & & & & & & & & & & & & & & & & & & & & & & & & & \\
\hline 14 & & & & & & & & & & & & & & & & & & & & & & & & & & & & & & & & & & & \\
\hline 15 & & & & & & & & & & & & & & & & & & & & & & & & & & & & & & & & & & & \\
\hline 16 & & & & & & & & & & & & & & & & & & & & & & & & & & & & & & & & & & & \\
\hline 17 & & & & & & & & & & & & & & & & & & & & & & & & & & & & & & & & & & & \\
\hline 18 & & & & & & & & & & & & & & & & & & & & & & & & & & & & & & & & & & & \\
\hline 19 & & & & & & & & & & & & & & & & & & & & & & & & & & & & & & & & & & & \\
\hline 20 & & & & & & & & & & & & & & & & & & & & & & & & & & & & & & & & & & & \\
\hline 21 & & & & & & & & & & & & & & & & & & & & & & & & & & & & & & & & & & & \\
\hline 22 & & & & & & & & & & & & & & & & & & & & & & & & & & & & & & & & & & & \\
\hline 23 & & & & & & & & & & & & & & & & & & & & & & & & & & & & & & & & & & & \\
\hline 24 & & & & & & & & & & & & & & & & & & & & & & & & & & & & & & & & & & & \\
\hline 25 & & & & & & & & & & & & & & & & & & & & & & & & & & & & & & & & & & & \\
\hline 26 & & & & & & & & & & & & & & & & & & & & & & & & & & & & & & & & & & & \\
\hline 27 & & & & & & & & & & & & & & & & & & & & & & & & & & & & & & & & & & & \\
\hline
\end{tabular}


Quadro 2 - Síntese da revisão da literatura: outras variáveis, coleta e análise de dados

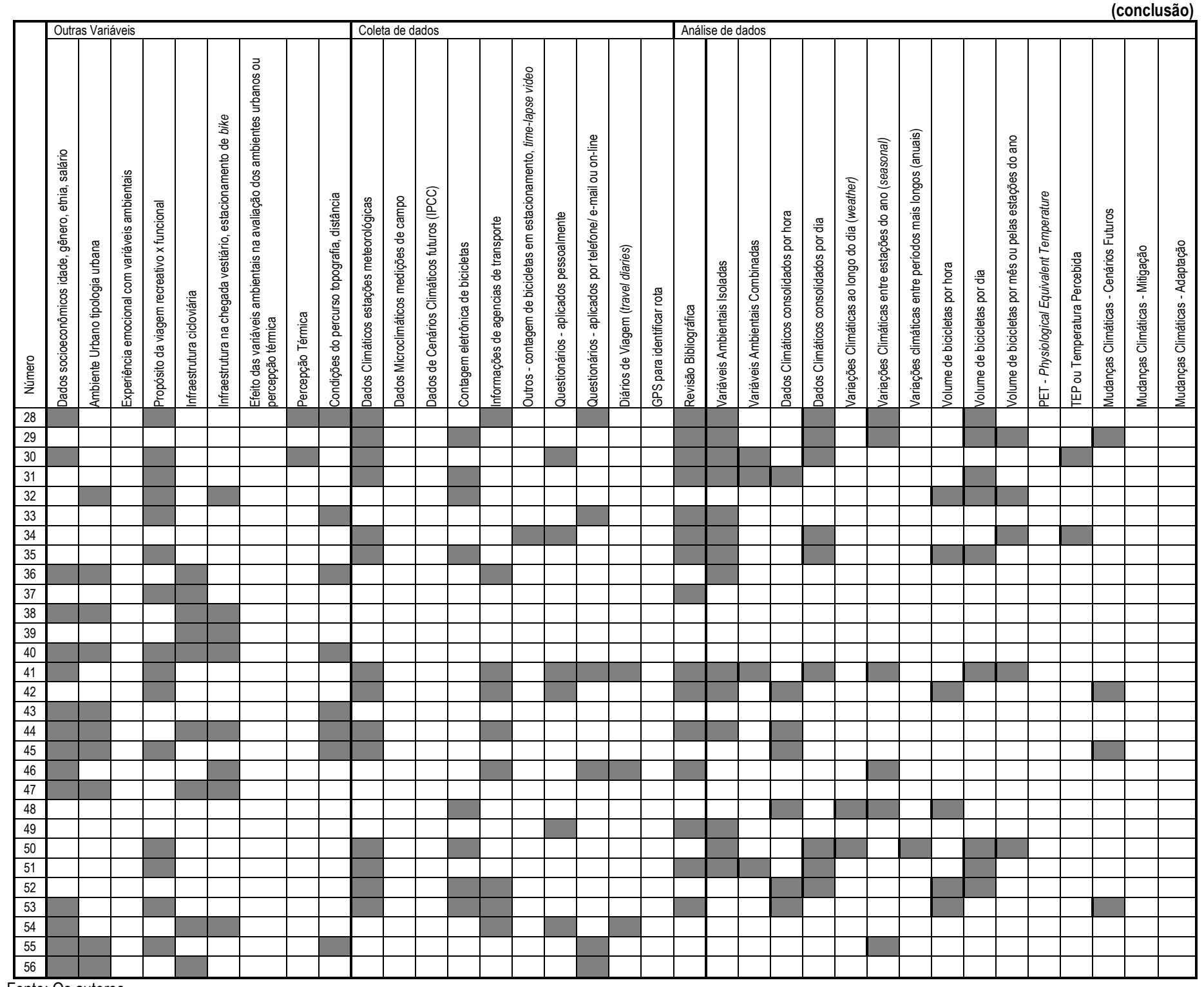

Fonte: Os autores

\section{Resultados e discussão}

Intuitivamente, somos menos propensos a pedalar em dias chuvosos, com temperaturas muito altas ou muito baixas. Umidade relativa do ar, ventos fortes, neve e gelo também parecem reduzir o uso da bicicleta (EMMERSON et al. 1998). Considerando as devidas limitações, é possível estabelecer uma correlação entre as variáveis climáticas e o uso da bicicleta em centros urbanos. Nesse sentido, alguns estudos identificaram ciclos anuais de fluxo de bicicletas em áreas urbanas, concentrando o maior número de viagens durante o verão, apresentando um movimento crescente na primavera e decrescente no outono, e atingindo os menores volumes durante o inverno (AHMED et al, 2010; BERGSTROM; MAGNUSSON,
2003; MIRANDA-MORENO; NOSAL， 2011; NANKERVIS, 1999; RICHARDSON, 2000).

Esse ciclo padrão de volume de bicicletas ao longo do ano é um indicador da influência das variações climáticas sobre a decisão individual pelo uso da bicicleta como meio de transporte (AAHEIM; HAUGE, 2005). Bergstrom e Magnusson (2003) comparam o uso de bicicletas para ir ao trabalho no verão (36\%) e no inverno (19\%), apresentando uma redução de $47 \%$.

Tin Tin et al. (2012) identificaram um impacto significativo dos aspectos ambientais (velocidade do vento, chuva, temperatura do ar e horas de sol por dia) nos volumes horários e diários de bicicleta, concluindo que dias ensolarados e mais quentes aumentam o volume de bicicletas, enquanto dias chuvosos e com vento geram um 
SPIGNARDI, Mariana de Cillo Malufe; MONTEIRO, Leonardo Marques.

A influência das variáveis microclimáticas na decisão pelo uso da bicicleta em centros urbanos: uma revisão da literatura

Quadro 3 - Síntese da revisão da literatura: resultados

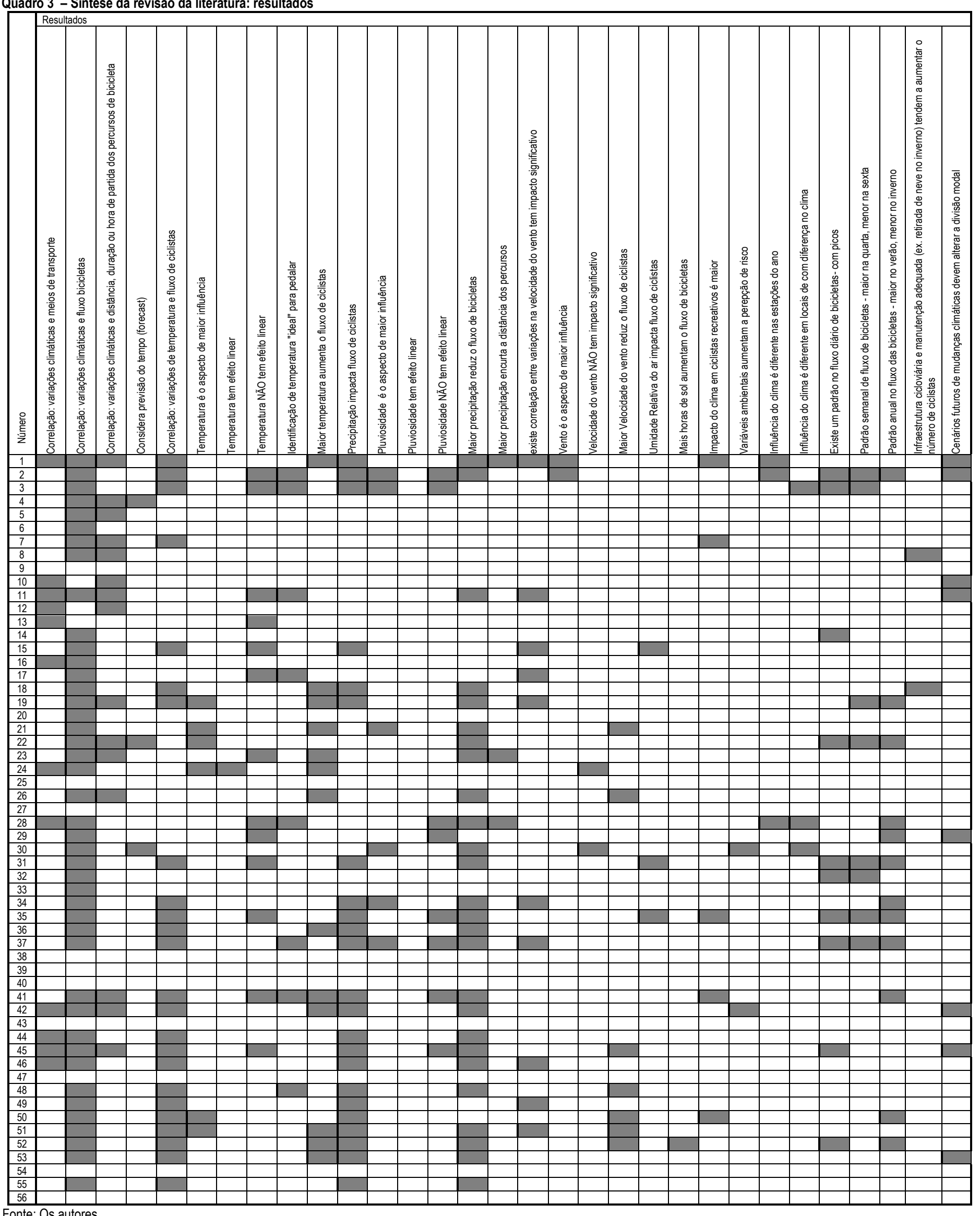


impacto inverso. Ele coloca que as variações climáticas influenciam mais os padrões de volume diário $(56 \%)$ do que os volumes dos ciclos horários $(23 \%)$ de bicicletas. Ahmed et al. (2010) concluem que aproximadamente metade das variações no fluxo de bicicletas em Melbourne, Austrália, resulta de variações nas condições climáticas. Mais de $60 \%$ alternam o dia do percurso e $40 \%$ alternam o horário de partida (AHMED et al., 2013b).

$\mathrm{Na}$ revisão da literatura, parte dos autores identificou a temperatura do ar como a variável ambiental de maior impacto e parte identificou a presença de precipitação como importante. Outros autores consideraram a velocidade do vento ou a umidade relativa do ar, como demonstrado na tabela 3 .

\section{Temperatura}

A variação na temperatura do ar é o aspecto ambiental que exerce maior influência na decisão pelo uso da bicicleta (EMMERSON et al., 1998; FLYNN et al., 2012; GALLOP; TSE, 2012; HANSON; HANSON, 1977; THOMAS et al., 2009, 2013), especialmente as temperaturas muito frias e muito quentes (NANKERVIS, 1999; NOSAL; MIRANDA-MORENO, 2014). Alguns autores identificam essa correlação, mas não a reconhecem como sendo a de maior impacto, vide tabela 3. Em geral, os autores consideram a temperatura média do período de medição, mas Smith e Kauermann (2011) afirmam que a correlação mais significativa é estabelecida com as temperaturas máximas diárias, que normalmente ocorrem entre 14:00 h e 17:00 h em Melbourne, Austrália.

O aumento na temperatura média do ar em climas temperados é, em geral, atrativo para os ciclistas, influenciando positivamente o fluxo de bicicletas (ELASSI et al., 2017; PARKIN et al., 2008; SABIR, 2011; THOMAS et al., 2013; TIN TIN et al., 2012), seja na ida ao trabalho ou em percursos recreativos.

Miranda-Moreno e Nosal (2011) relacionam o aumento de $1 \%$ na temperatura média do ar em Montreal, Canadá, a um acréscimo de aproximadamente $2,5 \%$ no fluxo de bicicletas. Sears et al. (2012) relacionam que a intenção de utilizar a bicicleta em um percurso utilitário em Vermont, EUA, aumenta $3 \%$ a cada $0,5^{\circ} \mathrm{C}$ na temperatura durante a manhã. Ambos os estudos foram realizados em regiões de clima temperado frio, sem estação seca e com verão temperado. Para um aumento de $10 \%$ na temperatura média do ar, Nosal e Miranda-Moreno (2014) verificaram um aumento no fluxo de bicicletas de $3,4 \%$ em rotas utilitárias e de $9,6 \%$ em rotas recreativas. Tin Tin et al. (2012) avaliaram o impacto do aumento de $1{ }^{\circ} \mathrm{C}$ da temperatura no volume de bicicletas em um período de uma hora e de 24 horas, onde o volume de bicicletas aumentou 3,2\% e 2,6\%, respectivamente. Ahmed et al.
(2012) verificaram que um aumento de $1^{\circ} \mathrm{C}$ aumentaria em $8 \%$ o volume diário de bicicletas.

O intervalo térmico considerado confortável para pedalar é estabelecido através das temperaturas que influenciam positivamente o número de percursos feitos de bicicleta. Phung e Rose (2008) identificaram que esse intervalo está entre $14^{\circ} \mathrm{C}$ e $40^{\circ} \mathrm{C}$ e que o fluxo atinge níveis máximos perto de $28^{\circ} \mathrm{C}$, que seria a temperatura "ideal para pedalar" em Melbourne, Austrália, onde o clima é temperado úmido, com verão temperado. Segundo Ahmed et al. (2012), a temperatura "ideal para pedalar" é de $24^{\circ} \mathrm{C}$ em Portland, EUA, e $20{ }^{\circ} \mathrm{C}$ em Brisbane, Austrália. Para Richardson (2000), o clima ideal em Melbourne é seco com temperatura de $25 \mathrm{C}$ e esse foi o ponto de partida para sua simulação em busca da proporção de dias com "clima ideal" e "clima não ideal" para se pedalar ao longo de um ano. Os resultados evidenciam que as viagens utilitárias acontecem em maior número do que as viagens recreativas nos dias com "clima não ideal". Ahmed et al. (2010) identificaram a mesma correlação não linear para valores de temperatura aparente em Melbourne, onde as temperaturas relacionadas ao maior fluxo de bicicletas variaram entre $25^{\circ} \mathrm{C}$ em St. Georges Road e $28^{\circ} \mathrm{C}$ em Canning street.

Sabir (2011) identificou que, em temperaturas baixas, abaixo de $0{ }^{\circ} \mathrm{C}$, a quantidade total de viagens não é alterada, mas que existe uma diferença na divisão modal: a demanda por viagens de bicicleta cai $7,7 \%$ e por transporte público aumenta $16,9 \%$, quando comparadas com o intervalo de temperaturas entre $0^{\circ} \mathrm{C} \mathrm{e} 10^{\circ} \mathrm{C}$. Winters et al. (2007) identificaram uma redução de $9 \%$ no fluxo de ciclistas a cada grupo de 30 dias de temperaturas muito baixas no período de um ano. El-Assi et al. (2017) colocam que temperaturas mais altas e níveis mais baixos de umidade relativa do ar, assim como níveis baixos de neve no solo, são positivos para gerar e atrair viagens de bicicleta em Toronto, Canadá, cidade de clima temperado frio sem estação seca e com verão temperado.

\section{Precipitação}

A presença de precipitação é uma das variáveis ambientais que mais influencia o volume de bicicletas em centros urbanos, vide tabela 3. Segundo Meng et al. (2016), as condições climáticas tropicais de Singapura são relativamente estáveis ao longo de todo o ano, a precipitação é a variável mais importante ao decidir pelo uso da bicicleta. No seu entendimento, as chuvas frequentes e altas temperaturas associadas aos altos índices de umidade relativa do ar contribuem para os baixos índices de uso da bicicleta, em torno de $1 \%$.

Nankervis (1999) avaliou o impacto das condições climáticas no fluxo de bicicletas em três universidades de Melbourne, Austrália, por meio do número de bicicletas 
no estacionamento da universidade, que nos dias de chuva forte foi reduzido pela metade. Ahmed et al. (2012) identificaram uma redução no volume de bicicletas de $70 \%$, se comparado aos períodos com ausência de precipitação, e que a chuva forte exerce o maior impacto, reduzindo o volume de bicicletas em $29 \%$, observando que a cada $1 \mathrm{~mm}$ de chuva houve uma redução de 3\% no volume de bicicletas. Tin Tin et al. (2012) mostraram que a cada $1 \mathrm{~mm}$ de chuva houve uma redução de $10,6 \%$ no fluxo de bicicletas, em períodos de medição de uma hora, e uma redução de $1,5 \%$ no volume diário de bicicletas. Richardson (2007) identificou que $8 \mathrm{~mm}$ de precipitação no dia reduzem o volume de bicicletas em $50 \%$, se comparado aos dias sem precipitação.

Além da intensidade, a duração da precipitação influencia a decisão sobre o uso da bicicleta, visto que 10 minutos de chuva reduzem a demanda por viagens em $1,6 \%$ e os percursos de bicicleta diminuem em $7 \%$, sugerindo que as pessoas trocam a bicicleta por transporte público ou automóvel (SABIR, 2011). Em uma perspectiva anual, Winters et al. (2007) mostram que, a cada 30 dias de chuva ao ano, existe uma redução de $16 \%$ no fluxo de bicicletas. A presença de precipitação em períodos anteriores ao início do percurso mostrou-se relevante na decisão dos ciclistas. Sears et al. (2012) verificaram que o número de ciclistas mais do que dobrou em dias sem precipitação no período da manhã.

A relação entre a intensidade da precipitação e o uso da bicicleta como meio de transporte não é linear (AHMED et al., 2010; AHMED et al., 2012; LIU et al., 2015; MATHISEN et al., 2015; NOSAL; MIRANDAMORENO, 2014; PHUNG; ROSE, 2008; RICHARDSON, 2000; SANEINEJAD; ROORDA; KENNEDY, 2012). Ahmed et al. (2010) concluem que o impacto da chuva forte (acima de $10 \mathrm{~mm}$ diários) reduz o volume de ciclistas duas vezes mais do que o impacto da chuva fraca/garoa (entre 0,2 e $10 \mathrm{~mm}$ diários), visto que a chuva fraca reduz em $13 \%$ os percursos de bicicleta e a chuva forte reduz em $40 \%$. Outros estudos apontam para a direção oposta, em que o impacto da chuva leve sobre os ciclistas é maior do que o impacto da chuva forte. Ahmed et al. (2012) concluem que a chuva fraca reduz em $9 \%$ o volume de bicicletas, enquanto a chuva forte tem impacto quatro vezes maior. A pesquisa de Phung e Rose (2008) em Melbourne mostra que a precipitação leve (com valores abaixo de $10 \mathrm{~mm}$ diários) reduziu o volume de bicicletas de $8 \%$ a $19 \%$, enquanto a chuva forte (acima de $10 \mathrm{~mm}$ diários) reduziu de $13 \%$ a $25 \%$, apenas um terço a mais.

Além de reduzir o número de viagens, a precipitação encurta as distâncias percorridas de bicicleta, exceto em viagens utilitárias, como os percursos para o trabalho de Aaheim e Hauge (2005). Ahmed et al. (2012) colocam que a influência da chuva forte é significante nas duas cidades pesquisadas, mas a interferência é diferente, pois reduz em $23 \%$ o volume de bicicletas em Portland e $33 \%$ em Brisbane.

\section{Velocidade do vento}

$\mathrm{O}$ aumento na velocidade do vento apresentou um impacto negativo no número de viagens de bicicleta, vide tabela 3 . Segundo Nankervis (1999), isso seria pelo maior esforço físico, devido ao aumento na dificuldade de pedalar. Ventos fortes tendem a agir mais sobre os ciclistas do que ventos mais fracos (THOMAS et al., 2009; HEINEN et al., 2011; FLYNN et al., 2012). Segundo Ahmed et al. (2010), os ventos fortes reduzem o fluxo de $15 \%$ a $20 \%$, dependendo do ponto de medição. Sears (2012) aponta para uma redução de 5\% na intenção de utilizar a bicicleta para um percurso utilitário para cada aumento de $1,6 \mathrm{~km} / \mathrm{h}$ na velocidade do vento, enquanto Tin Tin et al. (2012) identificaram uma redução no fluxo de bicicletas de 1,4\% nos ciclos de uma hora e de $0,9 \%$ nos ciclos diários para cada aumento de $1 \mathrm{~km} / \mathrm{h}$ na velocidade do vento.

Sabir (2011) conclui que o aumento na velocidade do vento influencia negativamente não apenas o número de viagens, como as distâncias percorridas. Os resultados de sua pesquisa mostram que ventos fortes reduzem a distância média percorrida em $2,3 \mathrm{~km}$, uma redução equivalente a 7,4\% na média total de distâncias percorridas.

Aaheim e Hauge (2005) identificaram, a partir de questionários, que o vento é uma variável significativa, apesar da impossibilidade de correlacionar os dados pela indisponibilidade dos mesmos. Nankervis (1999) coloca que aparentemente o aumento da velocidade do vento influencia negativamente o número de ciclistas, mas não identificou uma clara relação entre a velocidade do vento e o fluxo de bicicletas, enquanto Richardson (2000) coloca que a velocidade do vento, assim como a cobertura do céu por nuvens, não tem qualquer ação sobre o fluxo de bicicletas.

É um consenso que a influência das variáveis climáticas tem maior impacto sobre os ciclistas em percursos recreativos do que em percursos utilitários, como a ida ao trabalho ou à escola (AHMED et al., 2010; BRANDENBURG et al., 2007; HANSON; HANSON, 1977; SABIR, 2011; THOMAS et al., 2012; THOMAS et al., 2013), visto que esses percursos em geral são obrigatórios e não podem ser postergados ou facilmente cancelados (RICHARDSON, 2000). Brandenburg et al. (2007) observaram que os ciclistas utilitários são menos sensíveis às baixas temperaturas e à chuva, e o estudo de Spencer et al. (2013) mostra que os mesmos apresentam maior faixa de aceitação em relação às variáveis climáticas. 
Ahmed et al. (2013b) salientam que os ciclistas casuais mudam o dia em que pedalam em função das condições climáticas em $90 \%$ dos casos e os ciclistas funcionais em 50\%. Amiri e Sadeghpour (2015) entrevistaram ciclistas sob baixas temperaturas e constataram que $96 \%$ dos entrevistados estavam usando a bicicleta para ir ao trabalho. Richardson (2000) coloca que os dois tipos de percurso são influenciados pelas condições ambientais, em especial temperaturas muito altas ou muito baixas, mas que o número de viagens recreativas é menor em ambos os casos. As viagens recreativas são afetadas pela presença de precipitação, independente do índice ser baixo ou alto, enquanto as viagens utilitárias não são afetadas por pequenas quantidades de precipitação. Em relação às mudanças na temperatura do ar, o mesmo acontece: com a temperatura de $15^{\circ} \mathrm{C}, 70 \%$ das viagens utilitárias continuam a acontecer, enquanto apenas $45 \%$ das viagens recreativas se mantêm.

É possível identificar a mesma dinâmica por meio da comparação entre rotas predominantemente utilitárias e rotas predominantemente recreativas, sendo o fluxo desta última mais sensível às variações de clima (BRANDENBURG et al., 2007; RICHARDSON, 2000; THOMAS et al.; 2012). Phung e Rose (2008) identificaram que a rota Bay Trail de Melbourne, com seu caráter claramente recreativo, é mais sensível a ventos e chuva do que as rotas predominantemente utilitárias. Ao avaliar o impacto da precipitação no fluxo de bicicletas em cinco cidades norte-americanas, Nosal e Miranda-Moreno (2014) verificaram que, nas rotas predominantemente funcionais, a redução no fluxo de bicicletas variou entre $13 \%$ e $-47 \%$. Na Green Route, em Quebec, Canadá, onde predominam ciclistas recreativos, o impacto no fluxo foi de $-70 \%$.

Diferenças de gênero, idade, cultura e/ou aclimatação fazem com que os indivíduos respondam de forma diferente às variações climáticas. Em geral, mulheres, indivíduos de idade mais avançada, baixos índices de escolaridade e maiores salários são associados com uma menor propensão para pedalar (WINTERS et al., 2007). As variações de temperatura influenciam mais as mulheres do que os homens (AHMED et al., 2013; BERGSTRÖM; MAGNUSSON, 2003; SANEINEJAD; ROORDA; KENNEDY, 2012). Saneinejad, Roorda e Kennedy (2012) apresentam a tendência de que as temperaturas baixas influenciam 1,5 vezes mais as mulheres do que os homens. Ahmed et al. (2013) contam que as mulheres afirmaram ser mais influenciadas pelas condições climáticas do que os homens, $47 \%$ e $35 \%$, respectivamente.

Wardman et al. (2007) afirmam que homens tendem a pedalar e caminhar mais do que as mulheres e a probabilidade de usar a bicicleta para ir ao trabalho diminui à medida que a idade dos indivíduos aumenta. Não foi identificada uma correlação entre o uso da bicicleta e o nível de escolaridade e formação dos indivíduos. Saneinejad, Roorda e Kennedy (2012) sugerem que ciclistas mais jovens são mais sensíveis ao frio do que os ciclistas com mais idade. Temperaturas abaixo de $20^{\circ} \mathrm{C}$ influenciam negativamente ciclistas abaixo de 55 anos, havendo maior interferência sobre ciclistas abaixo de 25 anos, aumentando gradativamente para grupos com mais idade. O mesmo acontece com a influência da chuva, que é maior no grupo de indivíduos abaixo de 25 anos, enquanto os outros não apresentam sensibilidade.

Ahmed et al. (2013b) diferenciam as atitudes entre os ciclistas casuais, que fazem uso da bicicleta esporadicamente, e os ciclistas comprometidos. O primeiro grupo é mais vulnerável às alterações no clima (aproximadamente $75 \%$ dos entrevistados). No segundo grupo, 30\% consideram as variações climáticas na decisão pelo uso da bicicleta e salientam aspectos que os impedem de pedalar. Amiri et al. (2013), por meio da aplicação de um questionário em temperaturas muito baixas, identificam que $72 \%$ dos entrevistados eram ciclistas frequentes, pedalando mais de 10 vezes por semana ao longo do ano.

A análise dos ciclos semanais do fluxo de bicicletas evidencia maior atuação das variáveis ambientais aos finais de semana, o que reforça a hipótese de que percursos recreativos são mais suscetíveis do que percursos utilitários. Esse efeito está presente em cenários de chuva, aumento da umidade relativa do ar e mudanças na temperatura. A neve exerce uma influência semelhante em ambos os tipos de percurso (WADUD, 2014). Também foi identificado um padrão para os volumes semanais de ciclistas, concentrando o maior fluxo entre terça-feira e quarta-feira e os menores volumes no início e final da semana, sendo a sexta-feira o dia com o menor número de ciclistas (AHMED et al., 2010; AHMED et al., 2012; EMMERSON et al., 1998; GALLOP; TSE, 2012; MIRANDA-MORENO et al., 2013; NOSAL; MIRANDA-MORENO, 2014; PHUNG; ROSE, 2008).

Foram identificados também padrões de variação diária no volume de ciclistas utilitários, com períodos de pico comuns aos outros meios de transporte (AHMED et al., 2010; MIRANDA-MORENO et al., 2013; SMITH; KAUERMANN, 2000; TIN TIN et al., 2012). Ahmed et al. (2010) verificaram que o pico ocorre entre 7:00 h e 9:00 $\mathrm{h}$ e entre 16:00 h e 18:00 h, sendo o primeiro deles mais expressivo. Smith (2000) identificou picos de ciclistas utilitários entre 06:00 h e 09:00 h e entre 16:00 h e 19:00 h. Tin Tin et al. (2012) identificaram picos entre 7:00 h e 8:00 h e entre 17:00 h e 18:00 h. Miranda-Moreno et al. (2013) avaliaram cinco cidades norte-americanas e constataram que as ciclovias prioritariamente utilitárias apresentam o mesmo padrão: picos diários, semelhantes 
aos picos de tráfego de veículos (em torno de 8:00 h e de 17:00 h) e fluxo mais intenso no meio da semana (quartafeira). Ahmed et al. (2012) compararam duas cidades: Portland, EUA, e Brisbane, Austrália, e o horário de pico registrado foi entre 6:00 h e 9:00 h e entre 16:00 h e 19:00 h. O padrão de fluxo semanal segue os outros estudos, com maior fluxo na quarta-feira e menor fluxo na sexta-feira, com diferença de $17 \%$ entre esses dois dias.

Ciclistas com maior habilidade e experiência são menos afetados pelas condições climáticas desfavoráveis quando comparados aos ciclistas esporádicos. A chuva atua negativamente 2,5 vezes mais e a neve quatro vezes mais sobre ciclistas menos experientes (MOTOAKI; DAZIANO, 2015).

\section{Conclusão}

Sistemas de mobilidade urbana mais sustentáveis são essenciais na busca por cidades e economias de baixo carbono. A bicicleta tem um papel estratégico nesse cenário e as iniciativas de fomento a esse meio de transporte estão cada vez mais presentes. Porém, é importante entendermos quais aspectos influenciam a decisão pelo uso da bicicleta como meio de transporte.

Como mostra a revisão bibliográfica realizada, as variáveis microclimáticas influenciam, em maior ou menor escala, os usuários de transportes ativos, em especial os ciclistas. Os estudos foram realizados em cidades de clima temperado úmido ou temperado frio, onde as variações na temperatura média do ar e a presença de precipitação foram identificadas como os aspectos mais relevantes. Tanto a temperatura média como a presença de precipitação mostraram uma correlação não linear com o fluxo de bicicletas. Os estudos identificados foram realizados majoritariamente em regiões de clima temperado úmido com verão temperado ou quente, ou em clima temperado frio, sem estação seca e com verão temperado, onde a temperatura média no mês mais quente não passa dos $22^{\circ} \mathrm{C}$. As correlações identificadas não podem ser assumidas indiscriminadamente para outros climas, mas podem ser um ponto inicial de investigação para regiões com outros climas ou diferenças culturais intensas.

Em geral, os estudos avaliam o impacto individual de cada variável ambiental sobre o fluxo de bicicletas, mas a combinação das mesmas apresenta resultados ainda mais específicos. Como observado, o aumento na velocidade do vento exerce uma influência negativa no fluxo de bicicletas e a alta velocidade do vento associada à leve precipitação é o cenário de maior impedimento do uso da bicicleta. Os efeitos da temperatura, da umidade relativa do ar e do vento não podem ser analisados separadamente, visto que os indivíduos percebem a temperatura por meio da temperatura aparente/percebida, não da temperatura média do ar.

A percepção e o conforto térmico dos ciclistas são resultados da combinação de variáveis ambientais e determinantes na decisão do ciclista pelo uso da bicicleta. A revisão da literatura evidencia a influência individual das variáveis microclimáticas e aponta para a necessidade de um maior número de avaliações que as considerem em conjunto, estabelecendo uma relação com a sensação e preferência térmicas dos ciclistas.

Foi identificada a necessidade de estudos em regiões com outros climas para uma avaliação mais ampla da influência das variáveis microclimáticas na decisão pelo uso da bicicleta em centros urbanos. Pesquisas na América do Sul, em especial no Brasil, podem contribuir com esta investigação, visto que as pesquisas identificadas se concentram em países da Europa, América do Norte e na Austrália.

\section{Referências}

AAHEIM, H.; HAUGE, K. Impacts of Climate Change on Travel Habits: A National Assessment Based on Individual Choices. Oslo: CICERO Center for International Climate Research, 2005. (CICERO Report no. 2005:07.) Disponível em: < https://brage.bibsys.no/xmlui/handle/11250/191992>. Acesso em: 24 mar. 2018.

AHMED, F.; ROSE, G.; JAKOB, C. Impact of weather on commuter cyclist behaviour and implications for climate change adaptation. In: AUSTRALASIAN TRANSPORT RESEARCH FORUM, 33., 2010, Canbera. Proceedings ... Camberra: ATRF, 2010. http://atrf.info/papers/2010/index.aspx

AHMED, F. et al.. Commuter cyclists sensitivity to changes in weather: Insights from two cities with different climatic conditions. In: ANNUAL MEETING OF THE TRANSPORTATION RESEARCH BOARD, 91., 2012, Washington DC. Proceedings... Washington DC:TRB, 2012.

AHMED, F.; ROSE, G.; JAKOB, C. Commuter cyclist travel behavior: Examination of the Impact of Changes in Weather. Transportation Research Record: Journal of the Transportation Research Board, v. 2387, p. 76-82, 2013a. ISSN: 0361-1981. https://doi.org/10.3141/2387-09 
AHMED, F.; ROSE, G.; JACOB, C. Examining the impact of changes in weather on commuter cyclist's travel behavior. In: ANNUAL MEETING OF THE TRANSPORTATION RESEARCH BOARD, 92., 2013, Washington DC. Proceedings.. Washington DC:TRB, 2013b.

AMIRI, M., SADEGHPOUR, F. Factors affecting cycling patterns in cold weather. In: INTERNATIONAL CONFERENCE ON SUSTAINABLE DESIGN, ENGINEERING, AND CONSTRUCTION, 2012, Fort Worth. Proceedings ... Fort Worth: ASCE, 2012, p. 222-229, 2013. https://doi.org/10.1061/9780784412688.026

AMIRI, M.; SADEGHPOUR, F. Cycling characteristics in cities with cold weather. Sustainable Cities and Society, v.14, n. 1, p. 397-403, 2015. ISSN: 2210-6707. https://doi.org/10.1016/j.scs.2013.11.009

Bergstrom, A., MAGNUSSON, R. Potential of transferring car trips to bicycle during winter. Transportation Research Part A: Policy and Practice, v. 37, n. 8, p. 649-666, out. 2003. ISSN: 0965-8564. https://doi.org/10.1016/S0965-8564(03)00012-0

BOCKER, L., DIJST M., PRILLWITZ, J. Impact of everyday weather on individual daily travel behaviours in perspective: A literature review. Transport Reviews, v. 33, n. 1, p. 71-91, 2013a. ISSN: 1464-5327.

https://doi.org/10.1080/01441647.2012.747114

BOCKER, L., PRILLWITZ, J., DIJST, M. Climate change impacts on mode choices and travelled distances: a comparison of present with 2050 weather conditions for the Randstad Holland. Journal of Transport Geography, v. 28, p. 176-185, abr. 2013b. ISSN: 0966-6923. https://doi.org/10.1016/j.jtrangeo.2012.11.004

BOCKER, L.; THORSSON, S. Integrated weather effects on cycling shares, frequencies, and durations in Rotterdam, the Netherlands. Weather, Climate and Society, v. 6, p. 468-481, 2014. eISSN: 1948-8335. https://doi.org/10.1175/WCAS-D-1300066.1

BOCKER et al.. Em-route weather and place valuations for different transport mode users. Journal of Transport Geography, v. 47, p. 128-138, jul. 2015. ISSN: 0966-6923. https://doi.org/10.1016/j.jtrangeo.2015.06.003

BOCKER, L.; DIJST, M.; FABER, J. Weather, transport mode choices and emotional travel experiences. Transportation Research Part A: Policy and Practice, v. 94, p. 360-373, dez. 2016. ISSN: 0965-8564. https://doi.org/10.1016/j.tra.2016.09.021.

BRANDENBURG, C.; MATZARAKIS, A.; ARNBERGER, A. The effects of weather on frequencies of use by commuting and recreation bicyclists. In: MATZARAKIS, A.; FREITAS, C.R. de; SCOTT, D. (Eds.) Advances in Tourism Climatology. Freiburg: Berichte des Meteorologischen Institutes der Universität Freiburg, 2004. p. 189-197.

BRANDENBURG, C.; MATZARAKIS, A.; ARNBERGER, A. Weather and cycling - a first approach to the effects of weather conditions on cycling. Meteorological Applications, v. 14, p. 61-67, mar. 2007. ISSN:1469-8080. https://doi.org/10.1002/met.6

CLIFTON, K., CHEN, R. Representing weather in travel behaviour models: A case study from Sydney. In: AUSTRALASIAN TRANSPORT RESEARCH FORUM, 34., 2011, Adelaide. Proceedings ... Adelaide: ATRF, 2011.

http://atrf.info/papers/2011/index.aspx

CORCORAN, J. et al. Spatio-temporal patterns of a Public Bicycle Sharing Program: the effect of weather and calendar events. Journal of Transport Geography, v. 41, p. 292-305, dez. 2014. ISSN: 0966-6923. https://doi.org/10.1016/j.jtrangeo.2014.09.003

EL-ASSI, W.; SALAH MAHMOUD, M.; NURUL HABIB, K. Effects of built environment and weather on bike sharing demand: a station level analysis of commercial bike sharing in Toronto. Transportation, v. 44, n. 3, p. 589-613, 2017. eISSN: $1572-9435$. https://doi.org/10.1007/s11116-015-9669-z

EMMERSON, P.; RYLEY, T. J.; DAVIES, D. G. The impact of weather on cycle flows. Traffic Engineering and Control, v. 39, n. 4, p. 238-243, abr. 1998.

ENGBERS, L. H.; HENDRIKSEN, I. J.M. Characteristics of a population of commuter cyclists in the Netherlands: perceived barriers and facilitators in the personal, social and physical environment. International Journal of Behavioral Nutrition and Physical Activity, v. 7, n. 89, 2010. ISSN: 1479-5868. https://dx.doi.org/10.1186\%2F1479-5868-7-89

FLYNN, B.S. et al. Weather factor impacts on commuting to work by bicycle. Preventive Medicine, v. 54, n. 2, p. 122-124, fev. 2012. ISSN: 0091-7435. https://doi.org/10.1016/j.ypmed.2011.11.002 
GALLOP, C.; TSE, C. Tse, C. A seasonal autoregressive model of Vancouver bicycle traffic using weather variables. In: ANNUAL MEETING OF THE TRANSPORTATION RESEARCH BOARD, 91., 2012, Washington DC. Proceedings.. Washington DC:TRB, 2012.

GEBHART, K.; NOLAND, R. B. The impact of weather conditions on capital bikeshare trips. In: ANNUAL MEETING OF THE TRANSPORTATION RESEARCH BOARD, 92., 2013, Washington DC. Proceedings... Washington DC:TRB, 2013.

HANSON, S.; HANSON, P. Evaluating the impact of weather on bicycle use. Transportation Research Record, v. 629, p. 43-48, 1977. ISSN: 0361-1981.

HEINEN, E.; VAN WEE, B.; MAAT, K. Commuting by bicycle: an overview of the literature. Transport Reviews, v. 30, n. 1, p. 59-96, 2010. ISSN: 1464-5327. https://doi.org/10.1080/01441640903187001

HEINEN, E.; MATT, K.; VAN WEE, B. Day-to-day choice to commute or not by bicycle. Transportation Research Record: Journal of the Transportation Research Board, v. 2230, p. 76-82, 2011. ISSN: 0361-1981. https://doi.org/10.3141/2230-02

HELBICH, M.; BOCKER, L.; DJIST, M. Geographic heterogeneity in cycling under various weather conditions: Evidence from Greater Rotterdam. Journal of Transport Geography, v. 38, p. 38- 47, abr. 2013b. ISSN: 0966-6923.

https://doi.org/10.1016/j.jtrangeo.2014.05.009

LIU, C., et al. The influence of weather characteristics variability on individual's travel mode choice in different seasons and regions in Sweden. Transport Policy, v. 41, jul. 2015. ISSN: 0967-070X. https://doi.org/10.1016/j.tranpol.2015.01.001

MATHISEN, T.; ANNEMA, J.; KROESEN, M. The effects of weather and climate change on cycling in Northern Norway. European Journal of Transport and Infrastructure Research, v. 15, n. 2, p. 261-273, mar. 2015. ISSN: 1567-7141.

MENG, M.; ZHANG, J.; WONG, T. D. Zhang, J., Wong, Y.D. Effect of weather conditions and weather forecast on cycling travel behavior in Singapore. International Journal of Sustainable Transportation, v. 10, n. 9, p. 773-780, fev. 2016. ISSN: 15568334. https://doi.org/10.1080/15568318.2016.1149646

MIRANDA-MORENO, L. F.; NOSAL, T. Weather or not to cycle: Temporal trends and impact of weather on cycling in an urban environment. Transportation Research Record: Journal of the Transportation Research Board, v. 2247, p. 45-52, 2011. ISSN: 0361-1981. https://doi.org/10.3141/2247-06

MIRANDA-MORENO, L. F. et al.. Classification of bicycle traffic patterns in five North American Cities. Transportation Research Record: Journal of the Transportation Research Board, v. 2339, p. 68-79, 2013. ISSN: 0361-1981. https://doi.org/10.3141/2339-08

MOTOAKI, Y.; DAZIANO, R. A. A hybrid-choice latent-class model for the analysis of the effects of weather on cycling demand. Transportation Research Part A: Policy and Practice, v. 75, p. 217-230, mai. 2015. ISSN: 0965-8564. https://doi.org/10.1016/j.tra.2015.03.017.

NANKERVIS, M. The effect of weather and climate on bicycle commuting. Transportation Research Part A: Policy and Practice, v. 33, n. 6, p. 417-431, aug. 1999. ISSN: 0965-8564. https://doi.org/10.1016/S0965-8564(98)00022-6

NOSAL, T.; MIRANDA-MORENO, L. F. The effect of weather on the use of North American bicycle facilities: A multi-city analysis using automatic counts. Transportation Research Part A: Policy and Practice, v. 66, p. 213-225, aug. 2014. ISSN: 0965-8564 https://doi.org/10.1016/j.tra.2014.04.012

PARKIN, J.; WARDMAN, M.; PAGE, M. Estimation of the determinants of bicycle mode share for the journey to work using census data. Transportation, v. 35, n. 1, p. 93-109, 2008. ISSN: 1572-9435. https://doi.org/10.1007/s11116-007-9137-5

PHUNG, J.; ROSE, G. Temporal variations in usage of Melbourne's bike paths. In: AUSTRALASIAN TRANSPORT RESEARCH FORUM, 30., 2007, Melbourne. Proceedings ... Melbourne: ATRF, 2007. http://atrf.info/papers/2010/index.aspx

PUCHER, J.; BUEHLER, R. Why Canadians cycle more than Americans: a comparative analysis of bicycling trends and policies. Transport Policy, v. 13, n. 3, p. 265-279, mai. 2006. ISSN: 0967-070X. https://doi.org/10.1016/j.tranpol.2005.11.001 
PUCHER, J.; BUEHLER, R. Making cycling irresistible: lessons from the Netherlands, Denmark and Germany. Transport Reviews, v. 28, n. 4, p. 495-528, 2018a. ISSN: 1464-5327. https://doi.org/10.1080/01441640701806612

PUCHER, J.; BUEHLER, R. Cycling for Everyone: Lessons from Europe. Transportation Research Record: Journal of the Transportation Research Board, v. 2074, p. 58-65, 2008b. ISSN: 0361-1981. https://doi.org/10.3141/2074-08

RICHARDSON, A. J. Seasonal and weather impacts on urban cycling trips. Victoria: The Urban Transport Institute, 2000.21 . (TUTI Report 1-2000). Disponível em: < http://www.tuti.com.au/2000veloschweiz.pdf>. Acesso em: 26 mar. 2018.

SABIR, M. Weather and travel behaviour. 2011. $138 \mathrm{f}$. Theses (Doctoral in Economics and Business Administration) - Faculty of Economics and Business Administration, Vrije Universiteit Amsterdam, Amsterdã, 2011. Disponível em: < http://dare.ubvu.vu.nl//handle/1871/19500>. Acesso em: 24 mar. 2018.

SAELENS, B. E.; SALLIS, J. F.; FRANK, L. D. Environmental correlates of walking and cycling: findings from the transportation, urban design and planning literatures. Annals of Beharioval Medicine, v.25, n. 2, p. 80-91, 2003. ISSN: $1532-4796$. https://doi.org/10.1207/S15324796ABM2502_03

SANEINEJAD, S.; KENNEDY, C.; ROORDA, M. Modeling the Impact of Weather on Active Transportation. In: WORLD CONFERENCE ON TRANSPORT RESEARCH, 12., 2010, Lisboa. Proceedings ... Lisboa: WCTRS, 2010.

SANEINEJAD, S.; ROORDA, M. J.; KENNEDY, C. Modelling the impact of weather conditions on active transportation travel behaviour. Transportation Research Part D: Transport and Environment, v.17, n.2, p. 129-137, mar. 2012. ISSN: 1361-9209. https://doi.org/10.1016/j.trd.2011.09.005

SEARS, J. et al.. To bike or not to bike: seasonal factors for bicycle commuting. Transportation Research Record: Journal of the Transportation Research Board, v. 2314, p. 105-111, 2012. ISSN: 0361-1981. https://doi.org/10.3141/2314-14

SILVEIRA, M.; MAIA, M. Variáveis que influenciam no uso da bicicleta e as crenças da teoria do comportamento planejado. Transportes, v. 23, n. 1, p. 24-36, 2015. ISSN: 2237-1346.

SMITH, M. S.; KAUERMANN, G. Bicycle commuting in Melbourne during the 2000s energy crisis: A semiparametric analysis of intraday volumes. Transportation Research Part B: Methodological, v. 45, n. 10, p.1846- 1862, dez. 2011. https://doi.org/10.1016/j.trb.2011.07.003

SPENCER, P. et al.. The effect of environmental factors on bicycle commuters in Vermont: Influences of a northern climate. Journal of Transport Geography, v. 31, p. 11-17, jul. 2013. ISSN: 0966-6923. https://doi.org/10.1016/j.jtrangeo.2013.05.003

THOMAS, T.; JAARSMA, R.; TUTERT, B. Temporal Variations of Bicycle Demand in the Netherlands: Influence of Weather on Cycling. In: ANNUAL MEETING OF THE TRANSPORTATION RESEARCH BOARD, 88., 2009, Washington DC.

Proceedings... Washington DC: TRB, 2009.

THOMAS, T.; JAARSMA, R.; TUTERT, B. Exploring temporal fluctuations of daily cycling demand on Dutch cycle paths: the influence of weather on cycling. Transportation, v. 40, n. 1, p.1-22, jan. 2013. ISSN: 1572-943. https://doi.org/10.1007/s11116012-9398-5

TIN TIN, S. et al.. Temporal, seasonal and weather effects on cycle volume: an ecological study. Environmental Health, v. 11, n. 12, 2012. ISSN: 1476-069X. https://doi.org/10.1186/1476-069X-11-12

WADUD, Z. Cycling in a changed climate. Journal of Transport Geography, v. 35, p. 12-20, abr. 2014. ISSN: 0966-6923. https://doi.org/10.1016/j.jtrangeo.2014.01.001

WARDMAN, M.; TIGHT, M.; PAGE, M. Factors influencing the propensity to cycle to work. Transportation Research Part A: Policy and Practice, v. 41, n. 4, p. 339-350, mai. 2007. ISSN: 0965-8564. https://doi.org/10.1016/j.tra.2006.09.011

WINTERS, M. et al.. Utilitarian bicycling a multilevel analysis of climate and personal influences. American Journal of Preventive Medicine, v. 32, n. 1, p. 52-58, jan. 2007. ISSN: 0749-3797. https://doi.org/10.1016/j.amepre.2006.08.027

WINTERS, M. et al.. Motivators and deterrents of bicycling: Comparing influences on decisions to ride. Transportation, v. 38, n. 1, p. 153-168, 2011. ISSN: 1572-9435. https://doi.org/10.1007/s11116-010-9284-y 


\section{${ }^{1}$ Mariana de Cillo Malufe Spignardi}

Arquiteta e urbanista. Endereço Posta: Rua Jesuíno Arruda, 248. São Paulo, SP, Brasil, 04532-080.

\section{${ }^{2}$ Leonardo Marques Monteiro}

Arquiteto e Urbanista. Professor Doutor. Departamento de Tecnologia, Faculdade de Arquitetura e Urbanismo, Universidade de São Paulo. Endereço Postal: Rua do Lago, 876, São Paulo, SP, Brasil, CEP 05508-080. 